\title{
JULGAMENTO DAS CONTAS DO GOVERNO PRECISA SER FEITO COM RIGOR
}

Coluna publicada em 30.6.2015: <http://www.conjur.com.br/2015-jun-30/ contas-vista-julgamento-contas-governo-feito-rigor $>$

Nas últimas semanas o Tribunal de Contas da União, ao divulgar o relatório preliminar sobre as contas do governo federal de 2014, trouxe importantes questôes de Direito Financeiro de volta às manchetes dos principais meios de comunicação do país.

Os Tribunais de Contas, órgãos de fundamental importância na administração pública brasileira, sobre os quais já discorri em coluna anterior, ${ }^{1}$ exercem funçôes da maior relevância, entre as quais está a que os trouxe novamente ao centro das atenções.

Mais do que justificada uma necessária explicação que torne claros os fatos objeto deste debate, as atribuiçóes dos diversos entes envolvidos, os procedimentos que estão sendo seguidos e as consequências das decisões.

O Tribunal de Contas da União tem suas funções delineadas no artigo 71 da Constituição, sendo responsável por auxiliar o Congresso Nacional na missão de exercer o controle externo da administração pública federal, realizando a fiscalização contábil, financeira, orçamentária, operacional e patrimonial, quanto à legalidade, legitimidade, economicidade, aplicação de subvenções e renúncia de receitas. Para isso é dotado de autonomia institucional que lhe permite exercer essas funções com independência, não se subordinando nem mesmo ao Congresso Nacional, a quem devem prestar auxílio, como no caso ora mencionado, ao emitir parecer técnico sobre as contas apresentadas.

1 Notícias da Justiça e do direito desta quinta-feira, publicada em 25 de junho de 2015, no site do Conjur. 
A primeira dessas funções vem expressa no artigo 71, I, que lhe confere a competência para "apreciar as contas prestadas anualmente pelo Presidente da República, mediante parecer prévio que deverá ser elaborado em sessenta dias a contar de seu recebimento".

A prestação de contas da administração pública federal está entre as competências privativas do Presidente da República, nos termos do artigo 84, XXIV, da Constituiçãoo ("Compete privativamente ao Presidente da República prestar, anualmente, ao Congresso Nacional, dentro de sessenta dias após a abertura da sessão legislativa, as contas referentes ao exercício anterior"), sendo obrigação que, se não cumprida, tipifica crime de responsabilidade, ${ }^{2}$ já tendo sido efetivada com a entrega dos balanços gerais da União e do relatório do órgão central de controle interno à apreciação da Corte de Contas em 22 de abril de 2015.

É relevante ressaltar que se está diante de uma função consultiva exercida pelo TCU, uma vez que, em se tratando da prestação de contas da administração pública federal, o parecer emitido é opinativo, e tem por finalidade subsidiar a decisão final, a ser tomada pelo Congresso Nacional, a quem compete julgar anualmente as contas prestadas pelo Presidente da República (CF, art. 49, IX).

Parecer que deve ser técnico, de modo a demonstrar, pela análise dos dados apurados, a atividade financeira da administração pública federal no exercício anterior, avaliando-a sob os diversos aspectos previstos no artigo 70 da Constituição. E deve ser conclusivo, exprimindo a adequação das contas apresentadas aos princípios constitucionais e legais que regem a administração pública federal, informando sobre o cumprimento dos programas orçamentários, atingimento das metas e adequação ao sistema de planejamento orçamentário, além da observância dos limites e parâmetros estabelecidos na Lei de Responsabilidade Fiscal (Regimento Interno do TCU, art. 228).

Já o julgamento das contas, sob responsabilidade do Congresso Nacional, tem natureza política, não ficando vinculado ao parecer do TCU, sendo possível julgar em desacordo com a posição explicitada pelo Tribunal, uma vez que o Presidente da República é o condutor político dos planos de governo, tendo assim responsabilidade política, sujeita a julgamento de natureza política perante o Congresso Nacional. ${ }^{3}$ Aliás, não se pode deixar de registrar, função em que tem falhado gravemente, uma

2 Lei 1.079, de 1950, artigo 9, 2: "Art. 9o São crimes de responsabilidade contra a probidade na administração não prestar ao Congresso Nacional dentro de sessenta dias após a abertura da sessão legislativa, as contas relativas ao exercício anterior".

3 Helio Mileski, O controle da gestão pública, São Paulo, RT, 2003, p. 270. 
vez que não julga as contas desde 2002, ${ }^{4}$ uma omissão inaceitável, por estar entre as atribuições que, embora pouco conhecida do grande público, é das mais relevantes que exerce. Está-se, pois, diante de uma excelente oportunidade para chamar a atenção para esse fato e exigir que se cumpra aquela obrigação constitucional.

No caso em que a mídia concentrou suas atenções nas últimas semanas, foi divulgado o relatório e o projeto do parecer prévio sobre as contas do Presidente da República, ${ }^{5}$ apresentado pelo relator, Ministro Augusto Nardes, que deverá ser submetido à aprovação pelo Plenário e, então, restituído ao Congresso Nacional para instruir o julgamento das contas.

Em seu relatório, ${ }^{6}$ o Ministro Augusto Nardes apontou uma série de irregularidades, que foram destacadas pela imprensa, ante a relevância do caso, até por levantar a possibilidade de rejeição das contas do governo federal. Desta feita não se pode afirmar que "nunca antes na história desse país" isso tenha ocorrido, pois há registro de que tenham sido rejeitadas as contas em 1937, no Governo Getúlio Vargas. ${ }^{7}$

O relatório não chegou a ser apreciado pelo Plenário, que optou por decidir pela concessão de um prazo de 30 dias para que sejam apresentadas contrarrazóes sobre os indícios de irregularidades apontados, ${ }^{8}$ enumerados em 13 itens, com várias violaçôes ao princípio da legalidade, ausência do rol de prioridades na LDO, extrapolação do montante de recursos aprovados no orçamento de investimento para várias empresas, distorções que afetaram a confiabilidade de informações de indicadores e metas do PPA, ausência de contingenciamento quando necessário, entre outros. Postergou-se, assim, para além do prazo legal o envio ao Congresso Nacional do parecer do TCU sobre as contas do governo federal.

Entre as irregularidades apontadas, chamam a atenção as "pedaladas fiscais", assunto já tratado nesta coluna em 23 de setembro de $2014^{9}$ e 5 de maio de $2015,{ }^{10}$

4 Folha de S.Paulo, Congresso não analisa contas da Presidência desde 2002, em 17 de junho de 2015; Veja.com, Congresso não vota as contas do governo há 13 anos, em 14 de janeiro de 2015.

5 Regimento Interno do TCU (Resolução TCU 246, de 30.11.2011), art. 223.

6 Acesso em 21.10.2015: <http://portal3.tcu.gov.br/portal/page/portal/TCU/imprensa/noticias/noticias_arquivos/CG\%202014\%20_relat\%C3\%B3rio\%20preliminar.pdf>.

7 As 13 explicações que Dilma precisa dar. Revista Veja, versão digital, n. 2.431, de 24 de junho de 2015 .

8 O que não é previsto regimentalmente, nem praxe, uma vez que se trata de um projeto de parecer; no entanto, ante a gravidade da situação, e em atenção ao contraditório e ampla defesa, optou o Tribunal de Contas da União por fazê-lo, já havendo, inclusive, precedente (STF, SS 1.197-PE, rel. Min. Celso de Mello).

9 Atenção caro leitor, pedalar faz mal à saúde!

10 Cuidado, pedalar pode dar cadeia. 
evidenciadas pelos adiantamentos concedidos pela Caixa Econômica Federal à União para cobertura de despesas no âmbito dos programas Bolsa Família, Seguro Desemprego e Abono Salarial; pelo FGTS à União para cobertura de despesas no âmbito do Programa Minha Casa Minha Vida; e pelo BNDES à União para cobertura de despesas no âmbito do Programa de Sustentação do Investimento.

Irregularidades que, vale o registro, foram em boa parte denunciadas pelo valoroso trabalho do Ministério Público que atua junto ao TCU, instituição pequena no tamanho, grande na importância, pouco conhecida e que, em momentos como esse, evidencia sua dimensão e força como instituição fundamental no sistema de fiscalização das contas públicas e que tende a ocupar cada vez mais espaço no cenário nacional.

Vê-se, do que foi apurado pelo TCU, um quadro que evidencia desorganização das contas públicas, com uma série de atos que se mostram voltados a alterar e ajustar fatos e informaçôes com falseamento da verdade sobre as finanças públicas, de modo a dar-lhes uma melhor aparência, em desconexão com a realidade. A conhecida "contabilidade criativa", que já há muito vem sendo observada, e foi objeto desta coluna em 12 de fevereiro de 2013. ${ }^{11}$

Deixa clara a desconsideração pelos princípios que regem a gestão fiscal responsável, ao se constatar a liberação de recursos sem que houvesse receitas suficientes em período pré-eleitoral - justamente quando a legislação impõe maior rigor no controle das despesas públicas -, execução de despesas sem suficiente dotação orçamentária e inscrição irregular em restos a pagar, entre outras irregularidades.

Motivos que se mostram fortes o bastante para fundamentar uma possível e quase inédita rejeição das contas apresentadas, tendo em vista, principalmente, a demonstração de desapreço pelo ordenamento jurídico vigente, que pugna por uma gestão fiscal responsável, e tem na transparência um de seus princípios que não se coadunam com "maquiagens contábeis".

A rejeição das contas, além do prejuízo moral e político, pode levar à inelegibilidade por oito anos, ${ }^{12}$ sem prejuízo de os fatos que a motivaram darem ensejo a condenaçôes em diversas esferas, inclusive criminal, como já exposto em coluna recente. ${ }^{13}$

Já passou da hora de se levar o Direito Financeiro a sério, como já exposto neste mesmo espaço recentemente, ${ }^{14} \mathrm{e}$, embora a punição nem sempre seja o melhor cami-

11 Carnaval financeiro: contas "maquiadas" não vão tornar nosso país mais bonito.

12 LC 64, de 1990, art. 1º, I, $g$ (com redação dada pela LC 135, de 2010).

13 Cuidado, pedalar pode dar cadeia, publicado em 5 de maio de 2015.

14 Coluna $O$ direito financeiro precisa ser levado a sério, e 2015 começou mal, publicada em 10 de fevereiro de 2015. 
nho, por vezes torna-se necessária e o único que resta a ser seguido. Até mesmo para que dê a todos o exemplo de que tais fatos são graves e não devem se repetir. ${ }^{15}$

Daí porque órgãos como os Tribunais de Contas são dotados de garantias que lhes permitem agir com total independência e, assim, cumprir sua missão constitucional sem se sujeitar a pressões de qualquer natureza, e o mesmo se espera do Congresso Nacional. São em momentos como esse que as instituições demonstram sua força, valor e autonomia. Mostram sua solidez e a razão de ser no Estado Democrático de Direito.

15 “Se o TCU contribuir para gestores públicos e políticos levarem a sério a legislação e para evitar que tal situação se repita, já terá prestado um enorme serviço ao país”, As contas de Dilma e o papel do TCU. Revista Época, versão digital, ed. 889, de 22 de junho de 2015. 
